University of Windsor

Scholarship at UWindsor

\title{
Fuzzy cognitive mapping as a tool to define management objectives for complex ecosystems
}

\author{
Benjamin F. Hobbs \\ University of Windsor \\ Stuart A. Ludsin \\ University of Windsor \\ Roger L. Knight \\ University of Windsor \\ Phil A. Ryan \\ University of Windsor \\ Johann Biberhofer \\ University of Windsor
}

See next page for additional authors

Follow this and additional works at: https://scholar.uwindsor.ca/biologypub

Part of the Biology Commons

\section{Recommended Citation}

Hobbs, Benjamin F.; Ludsin, Stuart A.; Knight, Roger L.; Ryan, Phil A.; Biberhofer, Johann; and Ciborowski, Jan J.H., "Fuzzy cognitive mapping as a tool to define management objectives for complex ecosystems" (2002). Ecological Applications, 12, 5, 1548-1565.

https://scholar.uwindsor.ca/biologypub/1077

This Article is brought to you for free and open access by the Department of Biological Sciences at Scholarship at UWindsor. It has been accepted for inclusion in Biological Sciences Publications by an authorized administrator of Scholarship at UWindsor. For more information, please contact scholarship@uwindsor.ca. 
Authors

Benjamin F. Hobbs, Stuart A. Ludsin, Roger L. Knight, Phil A. Ryan, Johann Biberhofer, and Jan J.H. Ciborowski 


\title{
FUZZY COGNITIVE MAPPING AS A TOOL TO DEFINE MANAGEMENT OBJECTIVES FOR COMPLEX ECOSYSTEMS
}

\author{
Benjamin F. Hobbs, ${ }^{1,7}$ Stuart A. Ludsin, ${ }^{2,8}$ Roger L. Knight, ${ }^{3}$ Phil A. Ryan, ${ }^{4}$ Johann Biberhofer, ${ }^{5}$ \\ AND JAN J. H. CiBOROWSKI ${ }^{6}$ \\ ${ }^{1}$ Department of Geography and Environmental Engineering, Johns Hopkins University, \\ Baltimore, Maryland 21218 USA \\ ${ }^{2}$ Aquatic Ecology Laboratory, Department of Evolution, Ecology, and Organismal Biology, Ohio State University, \\ Columbus, Ohio 43212-1156 USA \\ ${ }^{3}$ Ohio Department of Natural Resources, Sandusky, Ohio 44870 USA \\ ${ }^{4}$ Ontario Ministry of Natural Resources, Port Dover, Ontario NOA INO Canada \\ ${ }^{5}$ Environment Canada, Burlington Ontario L7R 4A6 Canada \\ ${ }^{6}$ Department of Biological Sciences and Great Lakes Institute for Environmental Research, University of Windsor, \\ Windsor, Ontario N9B 3P4 Canada
}

\begin{abstract}
Defining objectives for ecological rehabilitation requires consideration of how an ecosystem responds to management. Validated quantitative models of physical, chemical, and biological processes are the best way to project such impacts; however, time, data, and model limitations often make these approaches impractical. An alternative is to encode expert knowledge about interactions among ecosystem components in a fuzzy cognitive map (FCM), which then translates that subjective, qualitative information into predictions of the effects of management on an ecosystem. Herein, we present the steps involved in constructing an FCM of an ecosystem, interpreting FCM output using multivariate statistics, and portraying the information in an easily communicated fashion. To illustrate these ideas, we rely on a complex ( $>160$ variables) ecosystem model built for the Lake Erie watershed under the auspices of the Lake Erie Lakewide Management Plan (LaMP). Based on our experiences in building this model, we also offer recommendations for increasing the efficiency of the model-development and interpretation process. Use of the FCM method in this case promoted constructive interaction among dozens of scientists, managers, and the public, as well as providing insights concerning the potential effects of broad classes of management actions upon the Lake Erie ecosystem. The analysis focused the attention of participants on four broad alternatives for the Lake. One represents present conditions, and another results from a decrease in nutrient inputs but an increase in stresses from land use and human disturbance. The two others involve reduced stress from nutrients and land use, with one having relatively more nutrients and less human disturbance and fishing. The latter ecosystem alternative was tentatively endorsed by LaMP management, and all four alternatives will be reviewed by the public.
\end{abstract}

Key words: cluster analysis; ecosystem management; ecosystem modeling; fisheries management; fuzzy cognitive maps; fuzzy sets; Lake Erie watershed; principal components analysis.

\section{INTRODUCTION}

An ecosystem objective can be defined as a desired future state of an ecosystem that can be used to guide management. Development of ecosystem objectives requires consideration of public priorities as well as an understanding of how the ecosystem responds to management actions (Bertram and Reynoldson 1992). Models play a crucial role in contributing to that understanding.

The most useful models for supporting the development of ecosystem objectives are ones that address all significant stakeholder concerns, capture key pro-

Manuscript received 31 July 2000; revised 30 April 2001; accepted 22 September 2001; final version received 10 January 2002

${ }^{7}$ E-mail: bhobbs@jhu.edu

${ }^{8}$ Present address: Department of Biological Sciences, University of Windsor, Windsor, Ontario N9B 3P4 Canada. cesses and components, respond plausibly to management actions, and are easy to explain and understand (e.g., Tester et al. 1997). The Grand Canyon (Walters et al. 2000), south Florida (Redfield 2000), and the Chesapeake Bay (Thomann 1998) are just some of the better known examples of ecosystems that have been the subject of comprehensive modeling efforts to guide management. However, a common difficulty in ecosystem management is that available process-based models rarely address the full range of ecological, social, and economic impacts of concern. For example, in the Neuse River basin, North Carolina, USA, managers are concerned about the gap between model capabilities and stakeholder concerns. Quantitative eutrophication models available for the basin focus on lower trophic-level dynamics (e.g., chlorophyll $a$ ). In contrast, stakeholders worry most about upper trophiclevel impacts, human health, and the fiscal cost of water-quality improvements (Borsuk et al. 2001). 
Hence, scientific judgments by experts are often required to project how management will affect valued ecosystem and societal components. The purpose of this paper is to describe how fuzzy cognitive maps (FCMs) can be used to systematically elicit and document expert judgment about components and their interactions, and to identify effective management strategies based on those judgments. We also summarize some lessons learned from an application of the FCM method to the definition of ecosystem objectives.

The FCM application we discuss was created by the Ecosystem Objectives Subcommittee (EOS) of the Lake Erie Lakewide Management Plan (LaMP; Lake Erie Lakewide Management Plan 2000). The LaMP is a binational effort to restore the ecological integrity of the Lake Erie ecosystem under the auspices of the Great Lakes Water Quality Agreement (GLWQA; Canada and United States of America 1987). In adopting a generalized ecosystem approach to planning, the LaMP recognizes that all components of the ecosystem are interdependent, including the water, biota, surrounding watershed, and atmosphere. Activities and aspirations of humans are viewed as integral parts of the ecosystem.

The need to recognize this interdependence is evident from the recent history of Lake Erie. Like many ecosystems, including the other Laurentian Great Lakes (Mills et al. 1993, Johnson et al. 1999), Lake Erie has experienced a variety of anthropogenic perturbations that have influenced all components of the ecosystem. The eutrophic conditions of the 1950s through the 1970s were caused by anthropogenic inputs of phosphorus (Hartman 1972). This eutrophication, as well as overfishing, caused the fish communities of Lake Erie to become highly degraded. Since then, phosphorus loads have declined, which together with improved fisheries management have allowed many once important fisheries to begin to recover (Ludsin et al. 2001). Another stress on the Lake Erie ecosystem has been invasion by exotic species (Mills et al. 1993). For example, zebra and quaff mussels (Dreissena sp.) have colonized the lake beginning in the late 1980s. This is argued to have led to biological oligotrophication of the lake (Holland et al. 1995), which may have caused reductions in fisheries (Ryan et al. 1999, but see Locci and Koonce 1999).

The GLWQA calls for the development of ecosystem objectives for each of the Great Lakes to guide their restoration. Ideally, objectives would be consistent with a return towards a pristine (resettlement) condition in the lake and watershed. This is not possible for Lake Erie, as the changes in the ecosystem have been extensive and, in many ways, appear irreversible (e.g., Burns 1985, but see Ludsin et al. 2001). As a result, "restoration" is not merely a scientific undertaking; it becomes a matter of social values, as choices need to be made among different possible mixes of resource quality and availability. For instance, further reduction of nutrient inputs towards presettlement levels may improve water quality, but may also lower the productivity of the Lake's fisheries (Ney 1996, Anderson et al. 2001). Because societal value judgments are required, LaMP objectives are being developed with input from an advisory Public Forum and the public at large.

The LaMP's approach to identifying ecosystem objectives has been to describe how management actions, such as changes in land use, control of phosphorus loads, and human exploitation and disturbance of fish and wildlife, can influence the Lake Erie ecosystem. Theoretically, different management strategies should yield different ecosystem configurations, or what the LaMP terms "ecosystem alternatives." Once these alternatives are defined, management agencies and the public will be asked to select an alternative to serve as the general objective.

Projecting how management actions can influence an ecosystem requires simulation modeling, a classic use of ecosystem models (Minns 1992). Because of the strength of connections among different parts of the Lake Erie ecosystem, LaMP participants felt strongly that a comprehensive model was needed that would allow exploration of the effects of management changes on the full range of aquatic and terrestrial ecosystem components and valued resource uses in the lake.

Numerous models previously have been developed to simulate processes and dynamics in the Great Lakes (see Colavecchia et al. 2000 for a review). Physical processes are emphasized in mass-balance models of phosphorus and silica, hydrodynamic models of currents and lake stratification, and watershed-runoff and sedimentation models. For instance, the Spatially Integrated Model for Phosphorus Loading and Erosion (SIMPLE) is a tool for assessing effects of land use activities upon phosphorus inputs (Matlock et al. 1994). As other examples, models have been developed to describe relationships among phosphorus loading, chlorophyll $a$, and hypolimnetic oxygen concentrations (e.g., DiToro and Connolly 1980). Often, a systems model will be a combination of several submodels. For example, Simons (1976) developed a hydrodynamic model for Lake Erie, and outputs from this model were then incorporated into chemical models (Lam and Simons 1976). Because of the importance of sports and commercial fisheries in Lake Erie, there also has been an emphasis on numerical models of fish populations and how they are regulated (e.g., Locci and Koonce 1999). Such models have often been used to examine interactions among growth, mortality, recruitment, and population abundance, as well as to identify exploitation limits. They also have been used to predict fish population size and structure changes.

Yet despite the abundance of quantitative models, none exist for many important components of the Lake Erie ecosystem (Colavecchia et al. 2000). Population models are available only for a handful of the $>100$ fish species resident in the Lake. Further, nearly all 
extant models focus on a small subset of the processes within the lake; physical and chemical processes in the lake and watershed have never been comprehensively linked with population models. For instance, there is no capability to project impacts of land use changes upon terrestrial and avian species, e.g., habitat is not represented explicitly in the most comprehensive fisheries model available (the Lake Erie Ecological Model: Locci and Koonce 1999). In addition, a severe time constraint imposed by LaMP management made it impossible to conduct original research to quantify the numerous missing cause-effect links. The lack of time and applicable process models meant that any comprehensive model for Lake Erie would have to rely heavily on expert judgment.

Fuzzy set theory has been previously proposed as a potentially useful means of capturing qualitative expert knowledge and using it to bridge gaps in ecological knowledge, and for characterizing uncertainty and imprecision in that knowledge (Bosserman and Ragade 1982, Salski et al. 1996, McGlade 1999, Mackinson 2001). As Salski (1992: 104) argues,

Sometimes the relations between the components of an ecosystem are not exactly known; sometimes we do not have any analytical model for these relations, or we have insufficient data for statistical analysis. In such a case, the idea is to build a model based on expert knowledge, knowledge which is also often not sharp, not precise.

A fuzzy representation of relationships may be particularly valuable for large, heterogeneous ecosystems, as their relationships are especially difficult to measure (Bosserman and Ragade 1982). Thus, to include relevant variables and relationships that are absent in more narrowly focused process-based models, the LaMP EOS explored the use of fuzzy set-based models. Ultimately, one such modeling approach, the FCM, was used to develop ecosystem objectives for Lake Erie. Owing to the subjective nature of the FCM inputs, the EOS inherently sacrificed precision in an attempt to achieve greater generality and realism (Levins 1966, Radomski and Goeman 1996).

In the next section, we provide a brief overview of the range of fuzzy set applications in applied ecology, including a summary of the LaMP Ecosystem Objectives Subcommittee's experience with fuzzy rule-based systems. The FCM modeling approach is subsequently introduced, including its formulation and parameterization. We then describe how multivariate statistics can be used to analyze FCM results and create a qualitative description of alternative ecosystem objectives. We conclude by summarizing the advantages and disadvantages of the FCM approach to ecosystem modeling, as well as offering advice for potential users of FCM based upon lessons learned from the Lake Erie LaMP application. Detailed documentation of the application itself can be found in Ludsin et al. (2002).

\section{Previous Fuzzy Set Applications in Ecology}

The most common ecological application of fuzzy sets has been to encode expert knowledge concerning how a habitat or population responds to ecological factors (e.g., soil substrate type, prey availability), especially when detailed process descriptions are unavailable (Salski 1992, Droesen 1996, Wu et al. 1996, Bock and Salski 1998). In such instances, fuzzy set operations have been used to define rules that relate linguistic statements of conditions (e.g., "forage availability is good" and "moisture conditions are excellent") to surrogates of population health (e.g., abundance). This is done by translating statements such as "good" or "excellent" into so-called fuzzy set membership numbers in the range $[0,1]$, which are then processed using standard fuzzy set operations (Zadeh 1965, Pedrycz $1991 b$, Kosko 1992). The higher the membership number, the greater the degree to which the object of interest belongs to a set.

As an example, expectations for the health of white bass (Morone chrysops) in Lake Erie could be assessed by asking if key requirements for the white-bass life cycle are met by a particular system state. Are spawning grounds sufficient in area and quality? Is surplus food available, for example, emerald shiners (Notropis atherinoides)? If all answers are "yes," then it is likely that a healthy white-bass population could exist. However, a white-bass population can still exist under less than optimal conditions. This idea can be represented by allowing for a membership number $<1$, or "partial membership," in sets that define the prerequisite conditions for white bass, and then using fuzzy set operations to combine those membership functions into a fuzzy number representing the membership of the white-bass population in the set "healthy population." For instance, if spawning grounds in a particular ecosystem were average, then they might be assigned a partial membership of 0.5 in the fuzzy set called "high quality spawning grounds." Meanwhile, if emeraldshiner abundance is low, a partial membership of 0.2 might be given for the ecosystem's membership in the fuzzy set "surplus food." A fuzzy index of overall white-bass population health could then be calculated as the intersection of these fuzzy sets, defined by Zadeh (1965) as $0.2=\operatorname{MIN}(0.5,0.2)$. This is the fuzzy analogue of the classic set-intersection operation, in which an object belongs to the intersection of the sets only if it belongs to each of the constituent sets. Other types of fuzzy set operations, such as unions (e.g., $\operatorname{MAX}(0.5,0.2))$ or weighted sums, can instead be used if deemed appropriate. The resulting fuzzy set membership value for the population can then translated back to a linguistic description (e.g., values in the range $[0.1,0.25]$ might be defined as "low abundance").

This rule-based fuzzy set approach is analogous to niche analysis in that the intersection of the fuzzy sets for a population represent its realized niche (Hutch- 
inson 1978). The potential for a sustained population (represented by a fuzzy-membership number) would increase from zero at the boundary to a maximum value within the bounded area. Consideration of more factors results in fuller definition of the niche as an $n$-dimensional hyper-volume.

Some instances of the use of fuzzy set operations to represent ecological processes include a model of the annual production of skylarks (Daunicht et al. 1996), characterizations of uncertainty in habitat suitability indices (Burgman et al. 2001), an assessment of finfish mariculture effects upon water quality (Silvert 2000), and a fuzzy representation of how nutrient and sediment inputs affect coral cover and diversity (Meesters et al. 1998). To describe just one example, Mackinson (2001) elicited fuzzy rules from managers, scientists, fishermen, and First Nations representatives, and then built those rules into a fuzzy logic expert system for predicting the structure and distribution of shoals of migratory adult herring. It is possible to involve hundreds and even thousands of experts in various fields when creating such systems, such as was done for the SimCoast model of impacts of human activities on coastal processes (Novello-Hogarth and McGlade 1997).

Fuzzy set methods can also be used to rank environmental management alternatives, as well as to quantify aggregate indices of environmental impact (Munda 1995, van der Werf and Zimmer 1998, Ducey and Larson 1999, Smith 1999, Stansbury et al. 1999, Freyer et al. 2000, Enea and Salemi 2001). In these applications, fuzzy set operations are used to combine qualitative statements about the attributes of management alternatives into a fuzzy index of overall desirability or impact. For instance, contaminant sources have been ranked by fuzzy logic in terms of the ecological risks they pose to Green Bay, Lake Michigan (Harris et al. 1994).

Classification is another use of fuzzy sets in ecology. Examples include classification of wetlands, assignment of species to compartments in a model of a marsh (Bosserman and Ragade 1982), recognition of forest succession patterns (Roberts 1989), and fuzzy cluster analysis of zooplankton community structure (Nicholls and Tudorancea 2001).

Unfortunately, rule-based fuzzy set models of the types just described do not readily simulate simultaneous interactions among multiple ecosystem components. For example, we are unaware of ecological applications of fuzzy rule-based systems that have considered feedback such as simultaneous effects of predators upon prey populations and vice versa. Thus, models based on fuzzy rules have limited usefulness for defining objectives for such systems. This conclusion has been borne out by the experience of the Lake Erie LaMP, described next; as a result of that experience, an alternative approach (the FCM) was turned to.

Early in the Lake Erie LaMP process, the Ecosystem
Objectives Subcommittee (EOS) attempted to use a verbal rule-based system to determine the extent to which stakeholder objectives for Lake Erie could be achieved by management. The first step was an October 1996 workshop attended by forty scientists. They were asked to define the conditions that have to be met to permit the existence of certain features, properties, or species in Lake Erie that had previously been identified as important by stakeholders. In other words, the scientists provided rules such as "Beaches will be swimmable (a stakeholder objective) if fecal coliform counts are low (a scientist-provided condition)," or "The potential for healthy walleye (Stizostedion vitreum) populations exists if the quantity and quality of spawning habitat is high." Over 4000 such rules were defined. However, the rules themselves were insufficient to project how management would affect the ecosystem because no algorithm was available to simultaneously assess their interactions.

In an attempt to develop such an algorithm, the EOS next tried to use a fuzzy set approach to process these rules. Fuzzy set theory was adopted because of its ability to handle imprecise or fuzzy data such as expert opinions. Fuzzy set membership functions and operations could have been derived from the workshop rules in the manner of Salski (1992) and Bock and Salski (1998).

Using fuzzy set theory in this manner, the LaMP EOS sought to establish a set of conditions and actions (e.g., eutrophic lake, high level of fishing) and then consult, or "query," the rules from the expert workshop to see what the implications of those conditions and actions would be for the ecosystem. Unfortunately, such a query approach turned out to be awkward because individual components, such as white bass, depend on multiple controlling factors. Further, simultaneous effects (e.g., emerald-shiner availability upon white bass, and white-bass predation upon emerald shiners) could not be handled by the rules database. The query approach was unable to project the subsequent reverberations that occurred in the states of other ecosystem components.

In 1997, the EOS considered alternative approaches for simultaneous and comprehensive consideration of all interactions among ecosystem components. However, they rejected the idea of simultaneously solving the 4000 rules mentioned above. The simultaneous solution of fuzzy rules is called the eigen fuzzy set problem (Pedrycz 1991a) because of its structure: $\mathbf{x}=\mathrm{R}(\mathbf{x})$, where $\mathbf{x}$ is a vector of fuzzy numbers, one per component of the system, and $\mathrm{R}($ ) is the set of rules expressed as fuzzy logic operators. Although algorithms for solving for $\mathbf{x}$ for certain forms of $\mathrm{R}$ ( ) have been proposed in the literature (Pedrycz 1991a), there are several reasons why the EOS deemed this approach impractical: there are restrictions on the types of fuzzy sets that can be processed (see Chung and Lee 1997); there is no way to predict whether a unique solution $\mathbf{x}$ 
will exist for a general set of fuzzy rules; the task of translating 4000 verbal statements into fuzzy logic is huge; and it is difficult to find software that can process such large numbers of simultaneous rules (indeed, we could find no examples of very large problems with feedback loops having been solved).

Instead, the EOS adopted the FCM methodology, which involves simple algebraic operations and can handle many fuzzy components simultaneously.

\section{Ecosystem Modeling Using Fuzzy COGNitive Maps}

An FCM consists of a set of numerical "causal concepts" or variables, $S_{j}$, together with directed "edges" or arcs that connect pairs of variables. Associated with each edge is a weight, $W_{j i}$, representing how the variable $S_{j}$ at the originating end of the arc influences the variable $S_{i}$ at the other end (Kosko 1992, McNeill and Thro 1994). Variables can represent logical propositions (e.g., "habitat is insufficient to support this species"), state variables (e.g., the abundance of a species), random events (e.g., an unusually cold winter), or management decisions (e.g., harvest quotas). In most FCMs, $W_{j i} \in[-1,1]$ are specified by experts based on empirical data or scientific opinion, while the $S_{j} \in[0$, 1] are either endogenous variables solved for by the model or are fixed boundary conditions. Depending on how the edges are defined, FCMs can include feedback loops, allowing complex system behavior to be modeled. This is the major advantage of this approach relative to rule-based systems based on fuzzy sets.

The FCM methodology is derived from the notion of a cognitive map (CM). A CM is a directed graph, defined as a set of nodes connected by directed edges. The nodes stand for problem variables (such as propositions or state variables), while the edges represent causal dependence of a variable upon other, predecessor variables. In traditional CMs, $S_{i}$ is either 0 (false or absent) or 1 (true or present), depending on whether any predecessor variable equals 1 (Axelrod 1976, Eden 1988, Marchant 1999). Some types of CMs set $S_{i}=1$ if instead a weighted sum of predecessor variables $\Sigma_{j}$ $W_{j i} S_{j}$ exceeds a threshold $U_{i}$. $W_{j i}$ can be negative or positive (and, of course, is zero if $j$ is assumed to have no direct influence on $i$ ). Some users of CMs assume $W_{i i}=0$, while others allow a variable to influence itself, as it would in a dynamic system with memory or lag effects (Tsadiras and Margaritis 1999). Classic CM analysis asks questions such as: What propositions are reachable from other propositions? In other words, can some specified propositions ever logically imply certain others?

Fuzzy cognitive maps differ from CMs by relaxing the CM assumption that a variable has to be either 0 or 1 (Kosko 1992). Because FCM variables can take on values between 0 and 1 , the $S_{i}$ can be viewed as classic fuzzy set membership numbers. (It is also possible to use a range of -1 to +1 in cases where negative values are meaningful.) FCMs are closely related to other system and knowledge representation approaches (Marchant 1999) such as influence diagrams (Buede and Ferrell 1993), artificial neural net models of causality and fuzzy evidential logic (Sun 1994), crossimpact simulation (Parashar et al. 1997) and fuzzy relational equations (Pedrycs 1991a, b). Each of these approaches involves definition of causal concepts and edges that designate direction, sign, and, in some cases, magnitude of influence on state variables of interest.

FCMs have previously been used to describe dynamic and steady-state behavior for a range of political, social, and engineering systems (Kosko 1992). Our search of the literature found only one ecological application of FCM (Radomski and Goeman 1996); there, a nine-variable FCM was used to model the effects of creel limits and length-based regulations on walleye populations and angler behavior in Minnesota. To our knowledge, the Lake Erie LaMP process is the first use of FCMs to model a large-scale ecological system. The Lake Erie application also is unique in that it involved dozens of scientists, managers, and members of the public in creating and interpreting the model.

An ecological application of FCMs could include variables $S_{i}$ for both biotic and abiotic ecosystem components. In practical terms, the value of a biotic variable in an ecosystem FCM can be viewed as a fuzzy variable indicating the potential to have a viable population of that species. Such variables can also be cautiously interpreted as an index of relative abundance; for example, the effect of white bass on prey species depends on the abundance of white bass. In contrast, variables for abiotic system components (e.g., suspended solids) could be interpreted as dimensionless indices of relative amount that depend upon predecessor variables (e.g., erosion) in a logical way.

Development of an FCM ecosystem model involves three steps: mathematical statement, definition of variables and edge weights, and testing and tuning. After describing these steps, we present a multivariate statistical approach to defining ecosystem objectives.

\section{Mathematical statement}

The value of $S_{i}$ in a FCM depends on the weighted sum of predecessor variables:

$$
S_{i}=f_{i}\left(\sum_{j} W_{j i} S_{j}\right)
$$

where $f_{i}(\mathrm{)})$ is a nondecreasing "actuation" function for variable $i$. Several forms can be used for such functions, including step functions, sigmoidal functions, or ramps (McNeill and Thro 1994). A ramp function with the following form was used for most variables in the LaMP application: 


$$
\begin{aligned}
& f_{i}\left(\sum_{j} W_{j i} S_{j}\right) \\
& \quad= \begin{cases}0 & \text { if } \sum_{j} W_{j i} S_{j}<L_{i} \\
\left(\sum_{j} W_{j i} S_{j}-L_{i}\right) /\left(U_{i}-L_{i}\right) & \text { if } L_{i} \leq \sum_{j} W_{j i} S_{j} \leq U_{i} \\
1 & \text { if } U_{i}<\sum_{j} W_{j i} S_{j}\end{cases}
\end{aligned}
$$

where $L_{i}$ is the lower threshold for activation (below which $S_{i}$ is zero), and $U_{i}$ is the upper threshold (above which $S_{i}$ becomes 1 ). In theory, the activation functions could instead involve fuzzy set operations (as in Salski 1992) rather than a simple weighted sum, although computational difficulties could result (Chung and Lee 1997). Activation functions also could include logical relationships, in which some predecessor variables have no substitutes and must be present (e.g., habitat), while other variables could be substitutes (e.g., different types of prey fish). In the LaMP application, however, the simpler weighted sum-based function was used because of software limitations and, more importantly, because weights were relatively easy to elicit from the participating scientists.

In FCMs, it is convenient to separate variables into endogenous variables $S_{\mathrm{E}_{i}}$, whose values are calculated by the FCM, and exogenous variables $S_{\mathrm{F}_{k}}$, whose values are fixed by the user. These fixed variables represent either boundary conditions, such as inputs from other ecosystems, or deliberate management actions. The activation functions can thus be written as follows:

$$
S_{\mathrm{E}_{i}}=f_{i}\left(\sum_{j} W_{\mathrm{E}_{j i}} S_{\mathrm{E}_{j}}+\sum_{k} W_{\mathrm{F}_{k i}} S_{\mathrm{F}_{k}}\right)
$$

or, using vector notation,

$$
\mathbf{s}_{\mathrm{E}}=\mathrm{f}\left(\mathbf{w}_{\mathrm{E}} \mathbf{s}_{\mathrm{E}}+\mathbf{w}_{\mathrm{F}} \mathbf{s}_{\mathrm{F}}\right) .
$$

This system involves $I$ variables $S_{\mathrm{E}_{i}}$ and $I$ equations, and can usually be solved for a fixed point equilibrium $\mathbf{s}_{\mathrm{E}}$, which is a function $\mathbf{s}_{\mathrm{E}}\left(\mathbf{s}_{\mathrm{F}}\right)$ of the fixed variables. Because $\mathbf{s}_{\mathrm{E}}\left(\mathbf{s}_{\mathrm{F}}\right)$ is an implicit function, numerical solution is usually required. Solving in this manner for the system response to fixed inputs allows exploration of how management actions (or inaction) might affect the system.

In practice, a fixed point equilibrium is commonly obtained by first defining an initial set of state values $\mathbf{s}_{\mathrm{E}, 0}$ and then iteratively calculating new values of the variables using the following Gauss-Seidel scheme (McNeil and Thro 1994):

$$
\mathbf{S}_{\mathrm{E}, t+1}=\lambda f\left(\mathbf{w}_{\mathrm{E}} \mathbf{S}_{\mathrm{E}, t}+\mathbf{w}_{\mathrm{F}} \mathbf{S}_{\mathrm{F}}\right)+(1-\lambda) \mathbf{s}_{\mathrm{E}, t}
$$

where $\lambda$ is a relaxation parameter whose purpose is to accelerate convergence, and $t$ is the iteration number. The calculation is repeated for $t=1,2,3, \ldots$ until convergence to a steady-state equilibrium is achieved. If the calculations do not converge, other values of $\lambda$ are tried. For our system, $\lambda=0.5$ yielded quick convergence.

It can be proven using Brouwer's fixed point theorem (Mas-Colell et al. 1995) that Eq. 4 has at least one solution if the functions are of the form of Eq. 2. However, the solution may not be unique. If activation functions (Eq. 1) are all piecewise linear, it is possible to apply sufficiency tests for uniqueness based on linear complementarity theory (Cottle et al. 1992). Unfortunately, those tests are inapplicable here because we used a mix of nonlinear and piecewise linear $f_{i}()$. Instead, we tested for multiple equilibria by using several distinct starting points $\mathbf{s}_{\mathrm{E}, 0}$ for the algorithm of Eq. 5; the same equilibrium always resulted. Because such sampling cannot absolutely prove that only one equilibrium exists, the user should always be aware of the possibility of multiple solutions to Eq. 4.

Some fuzzy set applications in ecology are concerned with system dynamics (e.g., Barros et al. 2000). In other fields, FCM models are sometimes used to simulate a dynamical system by setting $\lambda=1$ in Eq. 5 and assuming that $S_{\mathrm{E}, t}$ represents the system status at time $t$. In such cases, the system can exhibit either equilibrium, limit cycle, or chaotic behavior (McNeill and Thro 1994, Tsadiras and Margaritis 1999). To generate meaningful transient FCM behavior, experts should choose weights whose magnitudes appropriately reflect the amount of influence within the assumed time step of the model. Yet in the Lake Erie exercise, participants did not refer to a time step when choosing weights, so their weights should be viewed as containing, at best, ordinal information about steady-state relationships. Furthermore, $W_{\mathrm{E}_{i i}}>0$ in transient models and are usually close to 1 for small time steps. In contrast all $W_{\mathrm{E}_{i i}}=0$ in the Lake Erie model. Thus, we caution that the Lake Erie weights should only be used to obtain fixed point equilibria, and not transient solutions.

\section{Definition of FCM variables and edge weights}

In general, variables and weights in cognitive maps can be defined by face-to-face interaction among experts, questionnaires, and interpretation of documents (Axelrod 1976, Ulengin and Topcu 1997). For instance, Radomski and Goeman (1996) asked 29 fisheries biologists and managers to each qualitatively define the weights among the nine variables in their FCM as "little," "somewhat," and "a lot." These responses were then translated into a numerical scale ranging from -1 to +1 , and the final weights were defined as the mean of those values across the respondents.

An alternative approach is to convene a group meeting and define variables and weights collectively. The main advantage of such a face-to-face consensus approach is that participants can ask questions of each other and of the interviewer, which can minimize mis- 
TABLE 1. Categories and examples of Lake Erie fuzzy cognitive mapping variables.

\begin{tabular}{|c|c|c|}
\hline Category and subcategory & $\begin{array}{l}\text { No. } \\
\text { variables }\end{array}$ & Examples \\
\hline \multicolumn{3}{|l|}{ Management actions } \\
\hline Land use & 10 & $\begin{array}{l}\text { residential, agricultural, shoreline development, industrial, natural } \\
\text { landforms, harbors }\end{array}$ \\
\hline Land management & 4 & $\begin{array}{l}\text { best management practices for: nutrients; toxics; erosion; and ground- } \\
\text { water recharge }\end{array}$ \\
\hline Other pollution sources & 3 & $\begin{array}{l}\text { sewage treatment plant effluent, combined sewer overflows, industrial } \\
\text { thermal loads }\end{array}$ \\
\hline Harvest & 7 & hunting, trapping, commercial fishery, sports fishery, stocking \\
\hline Other human disturbance & 2 & small boating, disturbance, shoreline hardening \\
\hline \multicolumn{3}{|l|}{ Physical/chemical components } \\
\hline Nutrients and oxygen & 6 & total available $\mathrm{P}$, dissolved $\mathrm{Si}$, dissolved inorganic $\mathrm{N}, \mathrm{N}: \mathrm{P}$ ratio, anoxia \\
\hline Sediment & 4 & shoreline erosion, stream bedload, total suspended inorganic solids \\
\hline Transparency & 2 & nearshore transparency, offshore transparency \\
\hline Contaminant loading & 7 & atmospheric deposition, contaminant inventory, pesticides \\
\hline \multicolumn{3}{|l|}{ Biotic components } \\
\hline Environment/habitat & 15 & $\begin{array}{l}\text { submergent aquatic vegetation marsh, diked wetlands, riparian corri- } \\
\text { dor, beach, scrub shrub }\end{array}$ \\
\hline Specific vegetation & 6 & $\begin{array}{c}\text { purple loosestrife (Lythrum salicaria), reed grass (Phragmites commu- } \\
\text { nis), wild celery (Vallisneria americana) }\end{array}$ \\
\hline Micro-organisms and invertebrates & 21 & $\begin{array}{l}\text { bacteria, diatoms, edible phytoplankton, filamentous algae (Cladophora } \\
\text { spp.), large zooplankton, crayfish (primarily Orconectes propinquus } \\
\text { and Cambarus robustus), zebra mussels (Dreissena spp.) }\end{array}$ \\
\hline Fish & 23 & $\begin{array}{l}\text { yellow perch (Perca flavescens), smelt (Osmerus mordax), walleye } \\
\text { (Stizostedion vitreum), sea lamprey (Petromyzon marinus) }\end{array}$ \\
\hline Reptiles and amphibians & 9 & Fowler's toad (Bufo fowleri), snapping turtle (Chelydra serpentina) \\
\hline Birds & 42 & $\begin{array}{l}\text { Scaup (Aythya spp.), Mergansers (Mergus spp.), Double-crested Cor- } \\
\text { morant (Phalacrocorax auritus), Osprey (Pandion haliaeetus) }\end{array}$ \\
\hline Mammals & 10 & $\begin{array}{l}\text { muskrat (Ondatra zibethicus), river otter (Lutra canadensis), coyote } \\
\text { (Canis latrans), whitetail deer (Odocoileus virginianus) }\end{array}$ \\
\hline
\end{tabular}

understanding and facilitate knowledge exchange. Another advantage is that the exercise can be completed more quickly if the participants are gathered for a single meeting than if they are sent a questionnaire.

For these reasons, the LaMP EOS adopted the faceto-face approach to define the variables and initial values of the weights. They approached construction of the FCM in a "top-down" manner by first developing six general modules: (1) phyto- and zooplankton and benthos; (2) fish community; (3) amphibians and reptiles; (4) birds; (5) mammals; and (6) human activities and interventions (Colavecchia et al. 2000, Ludsin et al. 2002). EOS members then developed a list of variables that should be included in the FCM. This was done systematically by starting with one variable, and then listing all of the other variables that affect that variable. After repeating this for each variable, a finalized list of $\sim 160$ variables was generated, which could be grouped into three general categories: management actions, physical/chemical ecosystem variables, and biotic ecosystem variables. Table 1 further subdivides these categories and gives examples of each.

The next step was to determine the general nature of the links between variables. The group members considered each edge between variables $S_{j}$, and determined whether the net effect was positive or negative. For instance, walleye were concluded to be positively affected in the model by eight prey species, stream habitat, and trophic status, and were negatively influenced by two fishing actions, suspended solids, and cormorants (Phalacrocorax auritus). The group then categorized each link as strong, intermediate, or weak. Finally, they assigned to each link a numerical weight within the range of -100 to +100 . These values were divided by 100 to yield the final weights.

One of the weaknesses of the FCM approach is that it assumes that causality is either positive or negative, but not both. In the case of walleye, suspended solids can be beneficial up to a point because walleye prefer somewhat murky and low light conditions; beyond that point, however, suspended solids are harmful. In theory, Eq. 1 could be generalized to accommodate such nonmonotonic relationships (Bosserman and Ragade 1982). However, this is rarely done in practice. In the case of the Lake Erie model, we did not anticipate that suspended solids would reach levels that would be inimical to walleye.

As an example of FCM weights, consider Fig. 1, which represents alewife populations. Positive factors affecting alewife include five food groups and a habitat variable. Negative factors include commercial fishing and eight categories of predators. The weights portray the strength and sign of the effects.

The next step in the Lake Erie FCM parameterization was to choose values of $L_{i}$ and $U_{i}$ in Eq. 2 for each endogenous variable. For biotic variables, the rationale 


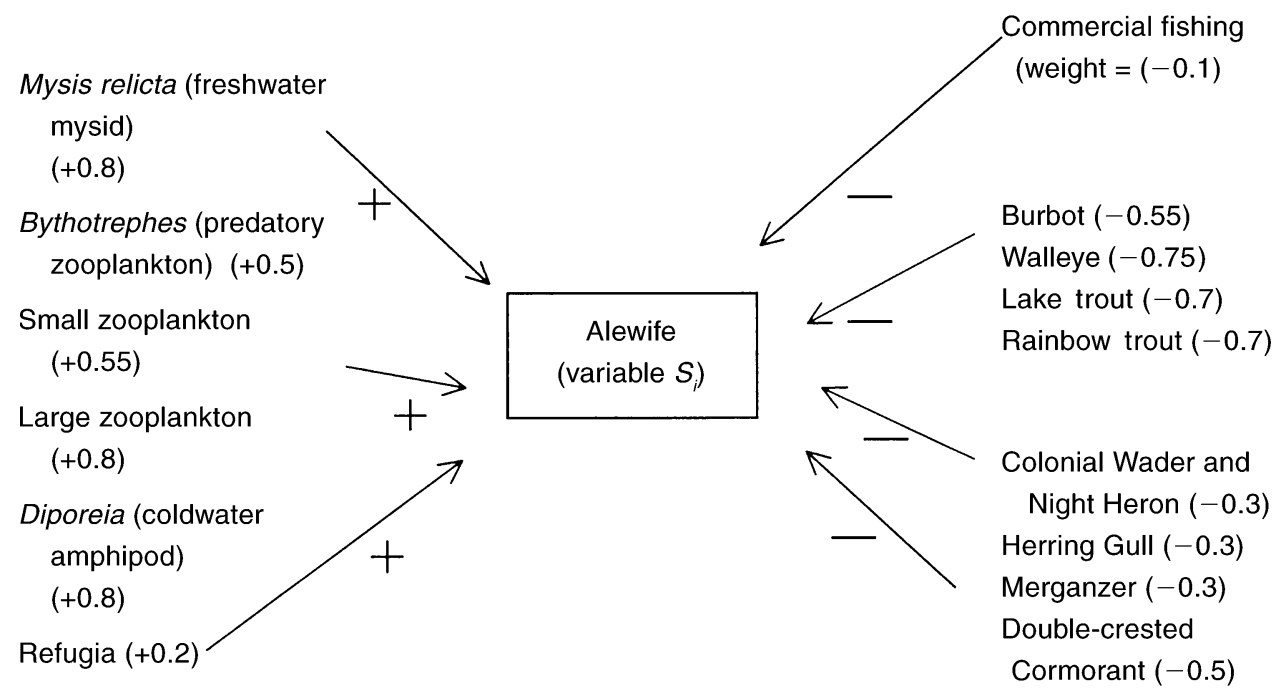

FIG. 1. Example of predecessor variables and associated edge weights (in parentheses).

used was as follows. If the weighted sum of predecessor variables falls below zero, this suggests that there is no potential for that variable; thus, $L_{i}=0$. On the other hand, if conditions are favorable (positive weighted sum for predecessor variables), then it is assumed that the variable would reach its maximum potential (i.e., $\left.S_{\mathrm{E}_{i}}=1\right)$ if $\Sigma_{j} W_{\mathrm{E}_{j i}} S_{\mathrm{E}_{j}}+\Sigma_{k} W_{\mathrm{F}_{k i}} S_{\mathrm{F}_{k}}$ attains $75 \%$ of its maximum possible value. As an example, the maximum value of this sum for alewife is 3.65 (Fig. 1), the sum of the positive weights on its predecessor variables; hence, $U_{i}=2.74$. The rationale for the $75 \%$ threshold is that not all food sources have to be present for a variable to reach its maximum potential.

\section{FCM model testing and tuning}

Once weights are assigned to all two-way interactions, the FCM model (Eq. 4) is then solved for a fixedpoint equilibrium using Eq. 5. This solution incorporates both the direct and indirect effects, which may result in end points that would not be anticipated on the basis of just the direct relationships. During the parameterization process, we ground truthed the model by ensuring that model behavior was qualitatively consistent with empirically established relationships. When we found inconsistencies, we reexamined and adjusted the parameters of the $f_{i}($ ). In FCM models, such adjustments are usually not automated (e.g., by least-squares methods). Instead, the modeler considers a range of weights and other parameters of the $f_{i}()$ that are plausibly consistent with the stated expert judgments, and tunes those parameters so that the system behavior and empirical data are more consistent. This is necessarily a subjective process, which reinforces our point that an FCM model is fundamentally a qualitative capturing of expert judgment that can be used to explore the implications of those judgments for ecosystem management.
In the case of the LaMP FCM model, a small number of interactions were tested for consistency with known relationships. After a preliminary set of runs, coefficients for a few $(<10 \%)$ of the model's variables were adjusted to conform to well-established effects of bottom-up (nutrient limitation) and top-down (predator structuring) forces (e.g., Hartman 1972, McQueen et al. 1986, Makarewicz and Bertram 1991, Ryan et al. 1999). Examples of these effects included dependence of algae on phosphorus levels and grazing by zooplankton, relationships of abundances of top predators and their prey, and the response of suspended solids to land use.

Tuning of the model was done by examining outputs after the model was exercised with a variety of values for the fixed variables $S_{\mathrm{F}_{k}}$, such as sewage treatment plant loadings of phosphorus. A sample of 129 values of the vector of $\mathbf{s}_{\mathrm{F}}$ was run through the model; threequarters of the vectors were randomly generated using a uniform $[0,1]$ distribution, assuming independence of the variables $S_{\mathrm{F}_{k}}$. The remainder of the sample consisted of predetermined values of the actions $(0,0.05$, $0.10, \ldots, 1)$ to stimulate a range of response from the model.

As an example of model testing, Fig. 2 portrays values of $S_{\mathrm{E}_{i}}$ for three components (blue-green algae, Cladophora, and near-shore transparency) plotted against a fourth variable, total phosphorus. The qualitative relationships agree with previously documented empirical relationships, and no model adjustments were necessary. (Note that plots such as Fig. 2 should be interpreted only in qualitative terms; what is important are changes in the variables, and not their absolute level on the relative $0-1$ scale. Thus, for example, the fact that algae variables do not equal zero when the phosphorus variable is zero matters less than that they are positively related.) Where a counterintuitive relation- 


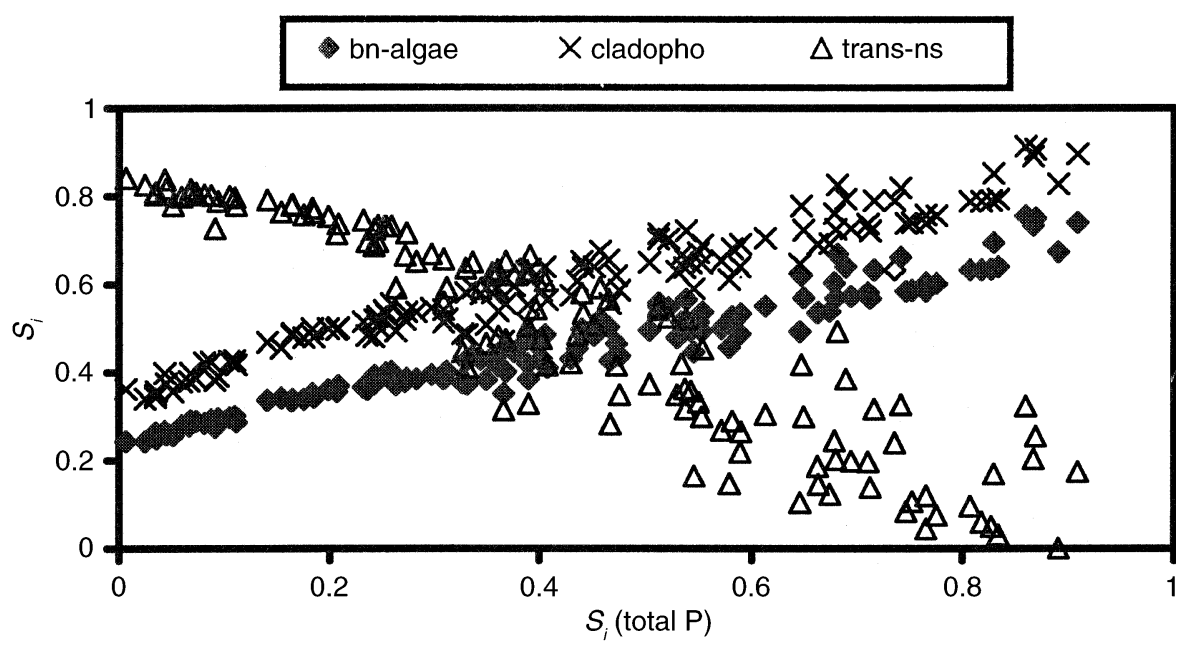

FIg. 2. Example of FCM model relationships used in tuning exercise (values of $S_{i}$ for blue-green algae, Cladophora, and nearshore transparency vs. values of $S_{i}$ for phosphorus loadings).

ship occurred, the structure of the model was examined to determine its cause. In most cases, the reasons were weights that, upon examination, were unreasonable or incorrectly entered; these weights were then adjusted to yield more reasonable outcomes. This was common in situations where links were established between components of modules that had been developed independently and then were linked. When the initial set of adjustments was completed, the results were reviewed by the Ecosystem Objectives Subcommittee, the LaMP managers, and a consultant. This resulted in the identification of some additional errors in inputs, and, eventually, a final FCM model.

A danger with such a process is that overtuning of a model could result in circular logic wherein model parameters are adjusted until anticipated values of all outputs are obtained, in which case nothing can be learned from the model. To guard against this circularity, a FCM model's outputs should only be checked against well-established relationships, as was done for the LaMP model. The model should not be tuned to produce agreement with preconceived notions that have little or no empirical basis. Our tuning of the Lake Erie FCM model attempted to strike this balance; adjustments were made only to ensure that obvious, welldocumented results were reproduced.

\section{Statistical ANAlysis AND InTERPRETATION OF FCM RESULTS}

An FCM model can help define ecosystem objectives by indicating what ecosystem responses are potentially feasible given a set of possible management actions. One approach to doing this would be to define several different values of the fixed-variable vector $\mathbf{s}_{\mathrm{F}}$ that represent different management actions and then explore how $\mathbf{s}_{\mathrm{F}}$ influences $\mathbf{s}_{\mathrm{E}}$, the response variables.

In this section, we describe an alternative, more systematic, approach to analyzing the effect of manage- ment. In this approach, a large number of values of $\mathbf{s}_{\mathrm{E}}$ calculated from a sample of inputs $\mathbf{s}_{\mathrm{F}}$ are statistically analyzed to determine general relationships between actions and ecosystem response. Multivariate statistical techniques, such as principal components analysis (PCA; Gauch 1982) and cluster analysis (Anderberg 1973), are useful for this purpose. PCA can be used to reduce the dimensions over which the results differ by collecting together suites of variables whose values are consistently correlated across the set of $\mathbf{s}_{\mathrm{E}}$. For the Lake Erie FCM, the behavior of $>30$ exogenous variables was reduced to four principal components that explained most of the variation in the results. Correlations of variables with the components were used to interpret the components' meaning. Cluster analysis can then be employed to group sets of similar $\mathbf{s}_{\mathrm{E}}$ alternatives together. This reduces the large number of $\mathbf{s}_{\mathrm{E}}$ alternatives to a much smaller number of broad options, or "ecosystem alternatives," representing values of $\mathbf{s}_{\mathrm{E}}$ that have broadly similar effects. Differences among those clusters can be interpreted using the principal components. The clusters represent a set of consolidated themes that can be used to present the tradeoffs inherent in ecosystem management to the public.

Below, we summarize the PCA and cluster analysis approaches. For each type of analysis, a general procedure is first introduced, after which we illustrate the interpretation of results using conclusions from the Lake Erie FCM model.

\section{Principal component analysis and its interpretation}

Let $S_{\mathrm{E}_{i h}}^{\prime}$ be defined as the standardized value of $S_{\mathrm{E}_{i}}$ in model run $h=1,2, \ldots, H$ (i.e., the deviation of $S_{\mathrm{E}_{i h}}$ from its mean, divided by its standard deviation), and let $\mathbf{s}_{\mathrm{E}_{h}}^{\prime}$ be the $h$ th sample vector of standardized variables. (Use of standardized variables means that all variables are equally weighted in the analysis; however, unequal weights can also be used in a PCA.) The first 


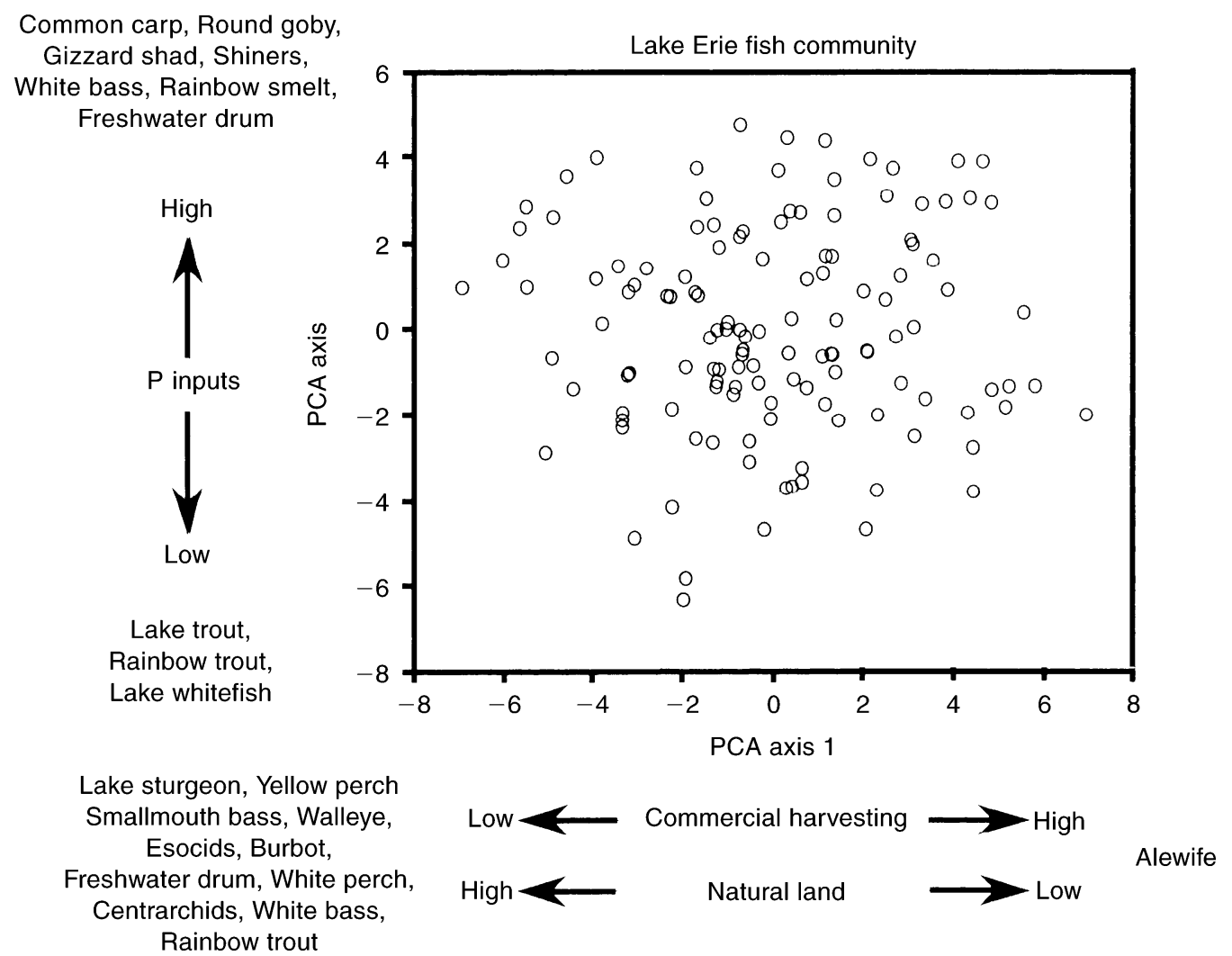

FIG. 3. PCA ordination diagram $(2$ units $=1 \mathrm{SD})$ of model results $(n=129)$ from the PCA of fish community variables. Each point represents the final configuration of one of the 129 runs of the model. Axis labels represent the exogenous variables whose values correlated most highly with the first two principal components (Table 2). Names of fishes represent endogenous variables whose values correlated most highly (positively or negatively) with the first two principal components (Table 3 ).

principal component or "axis" $\mathbf{p}_{1}$ is defined as a vector of unit length projected from the origin that minimizes the following residual variance:

$$
\sum_{h}\left(\mathbf{s}_{\mathrm{E}_{h}}^{\prime}-d_{1_{h}} \mathbf{p}_{1}\right)^{\mathrm{T}}\left(\mathbf{s}_{\mathrm{E}_{h}}^{\prime}-d_{1_{h}} \mathbf{p}_{1}\right)
$$

where $d_{1_{h}} \mathbf{p}_{1}$ is the projection of $\mathbf{s}_{\mathrm{E}_{h}}^{\prime}$ on an axis passing through the origin and point $\mathbf{p}_{1}, d_{1 h}$ is the distance from the origin to that projection, and $\mathbf{x}^{\mathrm{T}}$ is the transpose of vector $\mathbf{x}$. Thus, the first component explains more of the variance than any other possible axis. The $i$ th element of the component expresses the strength and direction of relationship (in the form of a correlation) between the axis and $S_{\mathrm{E}_{i}}$. The second component is a vector, $\mathbf{p}_{2}$, that explains most of the residual variance while being orthogonal to axis $\mathbf{p}_{1}$ (i.e., $\mathbf{p}_{1}^{\mathrm{T}} \mathbf{p}_{2}=0$ ). Up to a total of $N$ components can be defined analogously, where $N$ is the dimension of $\mathbf{s}_{\mathrm{E}_{h}}$ (Gauch 1982). Usually, however, only the first few components are interpretable and explain the bulk of the variance.

By correlating the individual variables $S_{i}$ with the principal component axes scores, the user can interpret the meaning of those axes. In particular, the correlations of the fixed variables $S_{\mathrm{F}_{k}}$ can indicate which actions (exogenous variables) most influence the system, while the correlations of the endogenous variables $S_{\mathrm{E}_{i}}$ indicate which ecosystem variables tend to covary with the actions. Of course, this interpretation is limited by the linearity of the PCA method; as a result, relationships among variables that are nonlinear and, especially, nonmonotonic (changing signs of slopes) may be distorted or missed altogether. There exist nonlinear multivariate statistical techniques that can be applied instead of PCA if a model's results are suspected to be highly nonlinear (e.g., detrended correspondence analysis, Jongman et al. 1995). However, since the $f_{i}($ ) are nondecreasing functions of weighted sums of variables, we would not anticipate nonmonotonicities or other severe nonlinearities in FCM outputs.

To illustrate the types of insight that can be gained from an FCM model, we interpreted the results of a PCA of only the Lake Erie FCM fish community variables. In so doing, we sought to identify which management actions most influenced fish-community variables in the Lake Erie FCM. The FCM runs analyzed were the 129 runs described in the section Ecosystem modeling using fuzzy cognitive maps: FCM model testing and tuning, above. Fig. 3 plots these runs on two axes representing the first two PCA components.

The first PCA component axis explains $>40 \%$ of the 
TABLE 2. Pearson $r$ correlation coefficients between PCA axis scores and values of management actions in the PCA analysis of fish-community variables.

\begin{tabular}{lcc}
\hline \hline \multicolumn{1}{c}{ Variable } & PCA axis 1 & PCA axis 2 \\
\hline Commercial fish harvesting & $0.56 \dagger$ & -0.03 \\
Natural land & $-0.55 \dagger$ & 0.18 \\
Phosphorus release from sewage treatment plants & -0.04 & $0.81 \dagger$ \\
Agricultural land & 0.24 & $0.67 \dagger$ \\
Residential land & 0.26 & $0.60 \dagger$ \\
Industrialized land & 0.26 & $0.53 \dagger$ \\
\hline
\end{tabular}

Notes: Only variables that were highly correlated with either PCA axis (i.e., $|r| \geq 0.5$; all Bonferroni corrected $P<0.00001)$ are included in this table. Daggers $(\dagger)$ denote these values. Positive $r$ values indicate variables that increase from left to right along PCA axis 1, whereas negative ones indicate variables that decrease from left to right along this axis. Positive $r$ values indicate variables that increase from bottom to top along PCA axis 2, whereas negative ones indicate variables that decrease from bottom to top along this axis.

standardized variance of the fish community variables, and is strongly correlated with two management variables, commercial harvesting $(r=0.56)$ and natural land availability ( $r=-0.55$; Table 2$)$. Thus, species listed on the left side of PCA axis 1 are ones that fare well under conditions that include low commercial harvesting and high natural land protection (Fig. 3). In general, these species tend to be of both commercial and sport value, including lake sturgeon, yellow perch, smallmouth bass, and walleye (Table 3, Fig. 3). The condition of these fish taxa declines from left to right along PCA axis 1 , as the value of the commercial harvest variable increases and natural land availability variable declines. Only the alewife variable correlates positively with high commercial harvesting and low natural land protection. These results suggest that managers of highly valued commercial and sport fisheries should be concerned with commercial fishery harvest, as well as land-use practices.

An additional $28 \%$ of the variation in the fish variables is explained by PCA axis 2 . This axis summarizes nutrient loadings, since phosphorus from sewage treatment plants (i.e., point sources) was strongly and positively correlated with PCA axis 2 scores (Table 2; Fig. $3)$. Values of variables associated with agricultural, residential, and industrial land development also were positively correlated with PCA axis 2 (Table 2), suggesting that nonpoint sources of phosphorus into Lake Erie also may drive variation in fish community structure. By examining the correlations of fish variables with PCA axis 2, we found that the condition of a variety of forage species tended to be positively associated conditions of high phosphorus loading (i.e., near the top of PCA axis 2; Table 3, Fig. 3). Lower

TABLE 3. Pearson correlation coefficients $(r)$ between PCA axis scores and fish variables in PCA analysis of fish-community variables.

\begin{tabular}{lrr}
\hline \hline \multicolumn{1}{c}{ Fish variable } & PCA & $\begin{array}{c}\text { PCA } \\
\text { axis } 2\end{array}$ \\
\hline Alewife & axis 1 & 0.23 \\
Lake sturgeon (Acipenser fulvescens) & $0.88 \dagger$ & -0.04 \\
Yellow perch (Perca flavescens) & $-0.92 \dagger$ & -0.05 \\
Smallmouth bass (Micropterus dolomieui) & $-0.89 \dagger$ & 0.26 \\
Walleye (Stizostedium vitreum vitreum) & $-0.88 \dagger$ & 0.27 \\
Family Esocidae (e.g., northern pike, Esox lucius) & $-0.80 \dagger$ & -0.33 \\
Burbot (Lota lota) & $-0.80 \dagger$ & -0.34 \\
White perch (Morone americana) & $-0.74 \dagger$ & 0.06 \\
Freshwater drum (Aplodinotus grunniens)/suckers (family Catostomidae) & $-0.74 \dagger$ & $0.52 \dagger$ \\
Family Centrarchidae (e.g., large mouth bass, Micropterus salmoides) & $-0.70 \dagger$ & -0.16 \\
Common carp (Cyprinus carpio) & -0.29 & $0.91 \dagger$ \\
Round goby (Neogobius melanostomus) & -0.38 & $0.82 \dagger$ \\
Gizzard shad (Dorosoma cepedianum) & 0.28 & $0.80 \dagger$ \\
Shiner species (e.g., emerald shiner; family Cyprinidae) & 0.46 & $0.73 \dagger$ \\
White bass (Morone chrysops) & $-0.59 \dagger$ & $0.67 \dagger$ \\
Rainbow smelt (Osmerus mordax) & 0.03 & $0.57 \dagger$ \\
Lake trout (Salvelinus namaycush) & -0.14 & $-0.68 \dagger$ \\
Rainbow trout (Oncorhynchus mykiss) & $-0.52 \dagger$ & $-0.58 \dagger$ \\
Lake whitefish (Coregonus clupeaformis) & -0.20 & $-0.50 \dagger$ \\
\hline
\end{tabular}

Notes: Daggers $(\dagger)$ denote fish taxa whose values are highly correlated to that PCA axis (i.e., $|r| \geq 0.5$; all $P<0.00001)$. Positive $r$ values indicate variables that increase from left to right along PCA axis 1, whereas negative ones indicate variables that decrease from left to right along this axis. Positive $r$ values indicate variables that increase from bottom to top along PCA axis 2, whereas negative ones indicate variables that decrease from bottom to top along this axis. 
phosphorus values are associated with reduced health of these species. In contrast, the values for economically important salmonids (e.g., lake trout and rainbow trout) were negatively associated with phosphorus values. Supporting previous investigations of aquatic systems undergoing eutrophication (Hartman 1972, Leach and Nepszy 1976), as well as oligotrophication (Ney 1996, Ludsin et al. 2001), our model suggests that management-driven changes in phosphorus inputs can indeed lead to fish-species turnover, which ultimately can cause tradeoffs in fisheries resources to occur.

In a similar manner, PCA was used to analyze which management actions $\mathbf{S}_{\mathrm{F}}$ in Table 1 most influenced the full suite of endogenous ecosystem variables $\mathbf{s}_{\mathrm{E}}$ in the Lake Erie FCM model. As outlined in Ludsin et al. (2002), four management actions, in decreasing order of importance, were most useful for understanding ecosystem structure: regulations on land use (i.e., agricultural, urban, industrial), point-source loading of phosphorus (i.e., sewage treatment plants), passive human disturbance (e.g., hiking, camping, boating), and commercial fish harvest. The first PCA axis (land use) explained $\sim 70 \%$ of the variance in the standardized $\mathbf{s}_{\mathrm{E}}$. Ultimately, these interpretations will be used to identify ecosystem objectives for Lake Erie.

Two issues that may diminish confidence in the interpretation of PCA results are sample error and weighting of variables. The effect of sample error can be gauged formally by resampling methods such as the bootstrap or, as in the case of the Lake Erie FCM, by generating and analyzing additional independent samples of runs. Inspection of factor loadings, the variation explained by each principal component, and the clusters indicated that sample error does not materially affect conclusions concerning which Lake Erie variables were most influenced by which management actions. In general, users should strive to use large sample sizes if a multivariate technique is to be used to analyze FCM results.

The issue of weighting of variables is important for two reasons. First, use of standardized scores for the variables in PCA means that all variables in $\mathbf{s}_{\mathrm{E}}$ have equal influence on the PCA results, whether or not they vary significantly in absolute terms. This impact of this assumption should be gauged by sensitivity analyses in which variables are instead weighted. This was done in the Lake Erie analysis by examining the results of a PCA upon the unstandardized variables; as in the case of sample error, the broad conclusions of the analysis were not significantly altered.

Weighting is important also because PCA results can be greatly influenced by decisions to include (or exclude) highly correlated variables in the analysis (Ramsey 1986). Indeed, we expected that the PCA of the Lake Erie FCM results would be sensitive in this manner. For instance, it is implicitly assumed in our PCA of the full set of variables that all elements in $\mathbf{s}_{\mathrm{E}}$ are equally important in making interpretations of ecosys- tem health. Hence, because our model included three times as many reptile, amphibian, mammal, and bird variables $(\sim 60)$ as fish variables $(\sim 20$; Table 1$)$, it should not be surprising that the most important PCA axis is related to land use (which directly affects the former species) rather than axes that represent direct stresses on the aquatic ecosystem (such as fishing and nutrient inputs).

In general, the effect of including or excluding correlated variables should be assessed by conducting two or more PCAs with different sets of variables. This was done in the Lake Erie analysis by comparing the PCA of the full set of variables with the PCA of just the fish community. We anticipated that an FCM with fewer terrestrial and avian species variables or more aquatic variables might result in more of the overall variance being explained by the direct aquatic stresses. This was indeed the case. The PCA of the fish community variables indicate that land use is still important to the aquatic ecosystem, but its principal components reflect increased influence by aquatic stresses compared to the PCA of all system variables.

\section{Cluster analysis and its interpretation}

A PCA of FCM model results for a large sample of values for exogenous variables $\mathbf{s}_{\mathrm{F}}$ can indicate what ecosystem variables covary most strongly with management-associated variables. Cluster analysis of the final configurations of those model runs can give additional insight, namely, the definition of a few broad alternatives for ecosystem management and a description of their ecological implications (in terms of the PCA axes). Cluster analysis attempts to assign individual points to a given number of subsets in such a way that the within-subset variance is minimized. In the Lake Erie case, within-cluster variance was defined as the sum of the squared deviations of the standardized scores of the Euclidean distances of the endogenous variables $\mathbf{s}_{\mathrm{E}_{h}}^{\prime}$ from their mean within the cluster to which they were assigned. This assignment problem is therefore a large-scale integer programming problem with a quadratic objective function in which the decision variables are $z_{h c}$, indicating whether $\left(z_{h c}=1\right)$ or not $\left(z_{h c}=0\right)$ sample $\mathbf{s}_{\mathrm{E}_{h}}^{\prime}$ is assigned to cluster $c$.

In general, solving for the minimal variance assignment is difficult; practical clustering algorithms use a variety of heuristic rules to identify relatively good groupings of $n$ observations. There are two basic classes of such heuristics (Anderberg 1973): agglomerative methods (which start with $n$ clusters and then systematically combine them into smaller numbers of clusters) and divisive methods (which start with one cluster with all $n$ observations and then iteratively divide it into larger numbers of clusters). In the case of the Lake Erie FCM analysis, the 129 runs were organized into seven clusters with dendrograms generated by Ward's method (Ward 1973, McCune and Mefford 1995). Ward's method is an agglomerative approach to minimizing within- 
cluster variance; however, like nearly all clustering methods, it cannot guarantee truly optimal clusters.

As explained in Ludsin et al. (2002), the endogenous state variable values from the 129 model runs of the Lake Erie FCM model were clustered to identify broad alternative futures for the Lake. There was some expectation by the EOS that the multiple runs of the FCM model would fall into a few natural clusterings, each cluster representing a distinctly different type of end state for the Lake Erie ecosystem. But fixed-point solutions of the FCM model (Eq. 4) are unlikely to show such behavior, given that the activation functions (Eq. 1) are linear or ramped. Indeed, if Eq. 1 is strictly linear (no upper or lower bounds), matrix manipulations of (Eq. 2) can be used to obtain $\mathbf{s}_{\mathrm{E}}$ as a linear function of the fixed actions $\mathbf{s}_{\mathrm{F}}$ :

$$
\mathbf{s}_{\mathrm{E}}=\left[\mathbf{R}-\mathbf{w}_{\mathrm{E}}\right]^{-1}\left[\mathbf{w}_{\mathrm{F}} \mathbf{S}_{\mathrm{F}}-\mathbf{L}\right]
$$

where []$^{-1}$ is the matrix inversion operator, $\mathbf{R}$ is a diagonal matrix with diagonal elements $\left(U_{i}-L_{i}\right)$, and $\mathbf{L}$ is a diagonal matrix with diagonal elements $L_{i}$. This linearity implies that if the actions $\mathbf{s}_{\mathrm{F}}$ are uniformly distributed (as they were for the Lake Erie analysis), then the outputs should also be uniformly distributed over some range determined by the weights, $U_{i}$, and $L_{i}$. Indeed, Fig. 3 exhibits a fairly uniform distribution. Thus, for the Lake Erie FCM model there should not be distinct clusters of model outcomes separated by zones with no points, unless this occurs randomly because of sample error in the inputs $\mathbf{s}_{\mathrm{F}}$. Hence, clustering will be a somewhat arbitrary endeavor that can be helpful for identifying different regions of the output space, but not obviously distinct groups.

The cluster analysis of the Lake Erie FCM defined seven clusters that were compared to each other and to an individual FCM model run whose exogenous variables $\mathbf{s}_{\mathrm{F}}$ were set to values that the EOS judged were characteristic of the 1960s. A challenge facing the EOS was to interpret these results so that the managers and the public could comprehend differences among the broad alternatives represented by the clusters. This task was difficult because of the high dimensionality of the FCM output. In particular, the clusters (called "ecosystem alternatives," or EAs) differ in terms of the mean values of $>160$ fuzzy numbers representing the status of management actions and ecosystem components. An additional challenge was the ordinal nature of the fuzzy variables. Even though only the relative position of fuzzy numbers on a dimensionless $[0,1]$ or $[-1,+1]$ scale is meaningful, we have found that users try to assign more meaning to absolute levels than can be justified. Therefore, the subcommittee decided to reduce the complexity of the results for presentation to the public by aggregating variables into approximate categories whose magnitude would be indicated by a four-level ordinal scale. (For details, see Ludsin et al. 2002.) Further, three of the seven clusters were judged to be unacceptable ecosystem alternatives and were dis- carded because they represent further degradation compared to present conditions and would therefore be incompatible with the goals of the Great Lakes Water Quality Agreement. Table 4 shows the results of this interpretation process for the remaining four clusters. In addition, pictorial interpretations, such as photographs showing varying levels of Cladophora prevalence on beaches, will be used to portray different levels of the actions and variables.

The first step of the interpretation simplification process was to define broad categories of ecosystem variables and actions that characterized the grouped outputs. The endogenous variables were sorted into 10 "ecosystem health" categories listed in Table 4, each containing up to 42 variables. The management actions were grouped into five categories. Means within these categories were computed to provide an initial basis for characterization of the clusters. The initial characterizations were then modified as follows to emphasize variables that significantly differentiated the results. First, exogenous variables with correlations $<-0.2$ or $>0.2$ with any of the first four principal components of the PCA were highlighted. Second, additional emphasis was placed on variables for which two or more of the clusters in Table 4 differed by $>0.1$ from the mean value of that variable.

We also differentiated the clusters according to how they influence certain specific "beneficial uses" (ecosystem services) of the Lake. The Great Lakes Water Quality Agreement defines 14 specific beneficial uses (Canada and United States of America 1987). From the perspective of the GLWQA, successful management of the Lake Erie ecosystem will realize the restoration of beneficial uses that are impaired when compared against their potential within the ecosystem. The EOS identified linkages between variables of the FCM and beneficial uses. Because not all beneficial uses were represented in the model, only seven of the 14 beneficial uses are listed in Table 4.

To facilitate comparison of the clusters, they were mapped onto the first two axes of the ordination diagram (analogous to Fig. 3) from the PCA of the full set of variables. Interpreting those axes using the factor loadings, the EOS concluded that the fourth of the seven clusters is closest to present conditions in the Lake ecosystem, while three of the other clusters represent improvements relative to present conditions. The other three clusters represent a deterioration, and, as mentioned above, were not considered further by the LaMP.

The four remaining clusters represent broadly different directions of change for the ecosystem (Table 4). EA3 is characteristic of conditions involving a decrease in nutrient inputs but a slight worsening of land use and human disturbance, while EA1 and EA2 both are associated with less nutrient input and improved land use relative to present conditions. Examination of where the clusters lie on PCA axes 3 and 4 indicate that EA1 end points involved more disturbance and 
TABLE 4. Management actions and response of various Lake Erie ecosystem components under the four ecosystem alternatives (EAs) relative to the 1960 s.

\begin{tabular}{|c|c|c|c|c|c|c|}
\hline Category & Ecosystem component & $1960 \mathrm{~s}$ & EA4 & EA3 & EA2 & EA1 \\
\hline \multirow{5}{*}{$\begin{array}{l}\text { Management } \\
\text { actions (effort) }\end{array}$} & Restoration of natural landforms & --- & 1 & 1 & 111 & 111 \\
\hline & Reduce impacts from agricultural practices & --- & 1 & 11 & 11 & 111 \\
\hline & Reduce impacts from urban land uses & -- & 1 & 11 & 11 & 111 \\
\hline & Reduce phosphorus loading & --- & 11 & 11 & 11 & 111 \\
\hline & Reduce human disturbance and harvest impact & --- & 1 & 1 & 11 & 1 \\
\hline \multirow{10}{*}{$\begin{array}{l}\text { Ecosystem } \\
\text { health }\end{array}$} & Environment/habitat & $\mathrm{O}$ & G & $\mathrm{O}$ & & \\
\hline & Plankton & O & (9) & 0 & & \\
\hline & Aquatic plants & $\bigcirc$ & $\bigcirc$ & 0 & O & \\
\hline & Benthos (cold-water) & $\bigcirc$ & O & O & $\bigcirc$ & \\
\hline & Benthos (cool-water) & O & (1) & G & G & \\
\hline & Amphibians & $\bigcirc$ & G & $\bigcirc$ & & \\
\hline & Reptiles & $\bigcirc$ & G & G & & \\
\hline & Fish & $\bigcirc$ & O & G & & \\
\hline & Birds & $\bigcirc$ & 9 & $\bigcirc$ & & (1) \\
\hline & Mammals & O & a & 0 & & 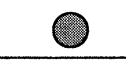 \\
\hline \multirow[t]{7}{*}{ Beneficial uses } & Natural environments & O & O & $\mathrm{O}$ & & \\
\hline & Less Cladophora on beach & 0 & O & & & \\
\hline & Water transparency nearshore & O & O & & & \\
\hline & Swimmability (bacteria) & $\bigcirc$ & O & & & \\
\hline & Absence of fish consumption advisories & O & O & & & \\
\hline & Absence of need to dredge & $\bigcirc$ & O & & & \\
\hline & Drinking water/absence of taste and odor & $\bigcirc$ & O & & & \\
\hline
\end{tabular}

Notes: For "Management actions," each person symbol represents a qualitative beneficial change and levels of effort and commitment required to achieve the desired change. A greater number of symbols signifies more effort, but an action that results in less environmental stress and potentially better overall ecosystem health. For "Ecosystem health" and "Beneficial uses," a "Consumer Reports" format is used to show differences in responses. A filled circle reflects the highest potential for improving ecosystem health or human use, an open circle the least, and the other symbols intermediate levels of potential.

commercial fishing than EA2 end points. On the other hand, nutrient inputs and land use stresses are greater in EA2. The net effect is that EA1 appears better in terms of water quality indices (the "beneficial uses" of Table 4), while fish, bird, and reptile populations are healthier in EA2. However, these characterizations should be interpreted cautiously because there remains significant within-cluster variance; therefore there are many possible variations within a cluster representing different combinations of particular management actions.

\section{Discussion}

The LaMP process for defining ecosystem objectives is not yet complete. In the summer of 2001, the LaMP managers expressed their preference for ecosystem al- ternative 2. In selecting EA2, the managers recognized that the actions most likely to achieve EA1 and EA2 are not mutually exclusive. As such, EA2 may become an interim goal towards achieving EA1, which many committee members considered to be the optimum. The process of reviewing and possibly revising the preferred alternative will be deferred until management actions thought to promote EA2 are demonstrated as being successful.

Ahead lies the public review process, followed by definition of the implied objectives for the Lake Erie ecosystem. The agencies and citizen groups participating in the LaMP are now preparing to present the process and rationale for selecting EA2 to the Lake Erie community at large. This consultation will afford an opportunity for stakeholder input, in particular a 
confirmation of which elements in EA2 are most valued by the community. Work is now starting on translating EA2 into specific indicators for defining requisite actions and measuring progress.

Although the process for defining objectives is unfinished, it is not too early to identify some of the benefits gained from using an FCM approach to represent a complex ecological system, along with some difficulties that might be avoided in future applications.

\section{Benefits of the FCM approach}

There are two types of benefits to using the FCM methodology for developing ecosystem objectives, one relating to communication and the other to insights concerning the response of the ecosystem. First, the FCM approach provides a framework for experts and stakeholders to express and debate judgments concerning linkages among ecosystem components. In the case of the Lake Erie FCM, judgments were obtained from representatives of 35 different organizations, including universities, government agencies, and nongovernmental organizations. Our observations of the process led us to conclude that the participants generally found it convenient to construct general rules for defining ecological relationships, as well as specifying the direction and magnitude of the interactions. Consensus was obtained in a reasonable amount of time (three one-day sessions) for a complex system $(>160$ social, physical, chemical, and biotic components). Further, most of these experts had never interacted before on a modeling exercise, and without use of the FCM framework, such interaction probably would not have been successful. Because the opportunity existed to debate each interaction, the LaMP Ecosystem Objectives Subcommittee was confident in the model. Therefore, we recommend the FCM method as a framework for large groups to share knowledge about large ecosystems. As with the Adaptive Environmental Assessment Process (Holling 1978), this information interchange can be the most valuable product of the process.

The second major benefit of the FCM approach is insight gained concerning potential states of a complex ecosystem and which management actions appear to be most influential. An advantage of the FCM methodology is that such system-level conclusions could be derived from a model that is built using only judgments about cause-effect linkages between individual ecosystem variables (i.e., two-way interactions). The FCM approach allows feedback loops, handles complexity, and can produce surprises. For instance, prior to the exercise, the EOS had little idea which of the 30 management actions would most influence the Lake Erie system. The FCM provided a way to hypothesize which ones actually might be most important. And, despite some tuning that was necessary early on, some unexpected results emerged. Most notable was the idea that land use appears to be as important as commercial harvest levels in influencing fish community structure.

One can argue that many of these conclusions could have been made without undertaking a multiyear modeling exercise. However, because of the breadth of interests involved in the LaMP (e.g., fishery scientists, anglers, water-quality managers, landowners), it was important to proceed deliberately so that the maximum number of participants would have confidence in the results. This is illustrated by the conclusion concerning additional phosphorus reductions. After scrutinizing the results of the FCM multivariate analysis, the EOS reached a consensus that deliberate phosphorus enrichment is undesirable, even though it has previously been argued that such enrichment is desirable for maintaining the productivity of Lake Erie (Stockner et al. 2000). Such a consensus would have been much less likely before the FCM exercise.

Of course, as in any modeling exercise, conclusions of any FCM analysis must be carefully qualified for several reasons. First, they are ultimately based on qualitative expressions of expert opinions about a large number of ecological processes for which there may be little empirical data. Second, FCM is based on a restrictive specification of cause-effect relationships in which the value of one variable is function of the sum of weighted influences by other variables. Third, conclusions about the relative importance of different management actions are derived from linear multivariate statistical analyses whose results depend on which variables are included and how they are weighted. Thus, predictions from a FCM should be viewed as being a set of possible logical implications of the experts' judgments whose robustness should be evaluated with extensive sensitivity analysis, and which should be tested (as hypotheses) whenever possible using empirical data and predictions from more realistic process-based models.

\section{Improving the efficiency and value of FCM analysis}

Our experience with the Lake Erie FCM leads to several recommendations for improving the utility of this approach in future applications. First, model creation should start with identification of variables. While the EOS's creation of a database and query system for the 4000 niche rules allowed for an integration of elements of the Lake Erie ecosystem and cross fertilization of expertise, the query system itself would not permit us to realistically assess system interactions. The query system also included many variables that were omitted in the ultimate FCM. Instead of stating rules first, it would have been more efficient to first identify the variables of the FCM, articulate rules just for those variables, and then specify causal weights for those rules. Such an approach would have reduced delivery time for the suite of possible ecosystem objectives.

Second, time should not be spent on attempts to in- 
terpret transient behavior of the model. Considerable effort was invested in resolving limit-cycle behavior observed during the first attempts to solve the FCM using $\lambda=1$ in Eq. 5. The limit cycles involved extreme swings in the values of the $S_{i}$. After both the EOS and the LaMP management spent much time trying to interpret the cycles, it was ultimately concluded that this dynamic behavior was a numerical artifact with no significance for Lake Erie. The relaxation parameter $\lambda$ was then varied, and the result was a set of interpretable fixed-point solutions.

Third, users should not expect that cluster analysis of the FCM results will identify unambiguously distinct groupings. In our study, this expectation led to some preliminary interpretations of the clusters as representing either/or alternatives, rather than a spectrum of possibilities. However, plots such as Fig. 3 show that the boundaries of clusters are somewhat arbitrary; there are no obvious concentrations of points. Cluster analysis of our model data served to break a more-or-less continuous pattern into separate groups as an aid to interpretation. If more or fewer than seven clusters had been created in the Lake Erie analysis, different conclusions might have resulted. Hence, results such as Table 4 must be viewed as points on a continuum, since compromises among those ecosystem alternatives are possible.

Fourth, users should avoid reading too much into the results of the multivariate analysis, and should subject those results to sensitivity analysis. For instance, a possible overinterpretation of the Lake Erie results would be a conclusion that because the land-use PCA axis explains three times as much variation in the full set of FCM variables as the phosphorus axis, land use should therefore receive, say, three times as much attention or funding as nutrient management. One reason why this would be an overinterpretation is that the fuzzy results should be viewed as being very approximate and ordinal in nature. A second reason is that the PCA results depend on which variables are included and whether they are standardized or otherwise weighted. Because the Lake Erie FCM has many more terrestrial and avian vertebrate variables than fish variables, the statistical results should therefore be more influenced by the former than the latter. As the two PCAs we have described show, this increases the apparent importance of land-use actions relative to fisheries and nutrient management. The list of terrestrial and avian variables could likely have been aggregated and shortened considerably (such as combining Piping Plover [Charadrius melodus] and "beach birds") without appreciably influencing the overall behavior of the system. A consequence of the proposed aggregation might be that the nutrient component (axis 2), along with the commercial fishing component (axis 4), would explain more of the variation of the results than previously.

Our final observation is that value of an FCM-based approach to developing ecosystem objectives may be most limited by the effectiveness of public involvement efforts. There are several challenges to obtaining management and public "buy in" to the results. One challenge will be to communicate the analysis procedure in a way that educates the public and managers and allows for informed recommendations. This will not be easy, as the Lake Erie Public Forum has pointed out that in order for the public consultation process to be effective, the information presented in Table 4 will need to be made more intuitively understandable. Education concerning the nature and importance of the management actions, ecosystem components, and beneficial uses listed therein must therefore be a focus of public outreach. Another challenge is that stakeholders are concerned with the costs to different economic sectors of the identified management actions, and will be reluctant to endorse one ecosystem objective over another without an understanding of those costs. Thus, a FCM analysis by itself provides insufficient information to choose a single ecosystem objective and must be complemented by other studies. Such studies are now underway for Lake Erie.

\section{CONCLUSION}

Building and analyzing a fuzzy cognitive map model of a complex ecosystem can promote valuable communication among diverse experts, along with public understanding of ecosystem processes and the limits and possibilities of management. The model framework can span scientific disciplines, supporting development of ecosystem management and linking with traditional hard science models. Thus, FCM models can have a complementary relationship to traditional scientific investigation and process-based models: an FCM model can use expert judgment to bridge gaps in processbased models, allowing available scientific knowledge to be more effectively used in management; and an FCM model can suggest modes of system behavior and relative magnitudes of influence that can be treated as hypotheses for testing by better models and data. As a FCM model's relationships are substantiated or revised based on comparisons with process-based models, the usefulness of a FCM model as a tool for exploring future scenarios will improve. The model outputs could then be an input to a more formal and quantitative analysis of decision risks and tradeoffs (e.g., Anderson et al. 2001).

\section{ACKNOWLEDGMENTS}

The authors offer thanks to the numerous individuals who participated in the LaMP expert workshops, Public Forum meetings, and management meetings, and provided numerous helpful suggestions. R. Griffiths first suggested use of the fuzzy set approach in this context, and designed the rulebased system. S. George and F. Norling, co-chairs of the Lake Erie LaMP management Work Group, provided invaluable encouragement and advice throughout this process, as did P. Bertram. M. Colavecchia led the writing effort for the first draft of the Lake Erie FCM documentation. R. Anderson and 
J. Kim provided research assistance, M. White gave valuable reviews, and J. S. Pang made suggestions concerning methods for determining the uniqueness of solutions. The Lake Erie FCM was implemented using Fuzzy Thought Amplifier software (version 5.015; McNeill and Thro 1994); M. McNeill was a continuous source of advice on its use, and developed a number of custom applications for us. Support for B. Hobbs was provided by USEPA STAR grant R825150 and USEPA Region V grant X98540501. Funding for creation and implementation of the FCM was provided by Environment Canada and USEPA through the Lake Erie LaMP program. Any errors or opinions are solely the authors' responsibility, and do not represent the positions of the sponsoring agencies.

\section{Literature Cited}

Anderberg, M. R. 1973. Clustering analysis for applications. Academic Press, New York, New York, USA.

Anderson, R. A., B. F. Hobbs, J. F. Koonce, and A. B. Locci. 2001. Using decision analysis to choose phosphorus targets for Lake Erie. Environmental Management 28:235-252.

Axelrod, R. M., editor. 1976. Structure of decision: the cognitive map of political elites. Princeton University Press, Princeton, New Jersey, USA.

Barros, L. C., R. C. Bassanezi, and P. A. Tonelli. 2000. Fuzzy modeling in population dynamics. Ecological Modelling 128:27-33.

Bertram, P. E., and T. B. Reynoldson. 1992. Developing ecosystem objectives for the Great Lakes: policy, progress, and public participation. Journal of Aquatic Ecosystem Health 1:89-95.

Bock, W., and A. Salski. 1998. A fuzzy knowledge-based model of population dynamics of the Yellow-necked mouse in a beech forest. Ecological Modelling 108:155-161.

Borsuk, M. E., R. T. Clemen, L. A. Maguire, and K. H. Reckhow. 2001. Stakeholder values and scientific modeling in the Neuse River Watershed. Group Decision and Negotiation 10:355-373.

Bosserman, R. W., and R. K. Ragade. 1982. Ecosystem analysis using fuzzy set-theory. Ecological Modelling 16:191208.

Buede, D. M., and D. O. Ferrell. 1993. Convergence in problem solving: a prelude to quantitative analysis. IEEE Transactions on Systems, Man, and Cybernetics 23:746-765.

Burgman, M. A., D. R. Breininger, B. W. Duncan, and S. Ferson. 2001. Setting reliability bounds on habitat suitability indices. Ecological Applications 11:70-78.

Burns, N. M. 1985. Erie: the lake that survived. Rowman and Allanheld, Totowa, New Jersey, USA.

Canada and United States of America. 1987. Great lakes water quality agreement of 1978. Agreement, with annexes and terms of reference, between the United States and Canada signed at Ottawa, November 2, 1978; and Phosphorus load reduction supplement signed October 7, 1983 as amended by Protocol signed November 18, 1987. Consolidated by the International Joint Commission, Windsor, Ontario, Canada.

Chung, F.-L., and T. Lee. 1997. A new look at solving a system of fuzzy relational equations. Fuzzy Sets and Systems 88:343-353.

Colavecchia, M., S. Ludsin, P. Bertram, R. Knight, S. George, H. Biberhofer, and P. Ryan. 2000. Identification of ecosystem alternatives for Lake Erie to support development of ecosystem objectives. Ecosystem Objectives Subcommittee, Lake Erie Lakewide Management Plan, Environment Canada, Burlington, Ontario, Canada.

Cottle, R. W., J. S. Pang, and R. E. Stone. 1992. The linear complementarity problem. Academic Press, New York, New York, USA.

Daunicht, W., A. Salski, P. Nohr, and C. Neubert. 1996. A fuzzy knowledge-based model of annual production of skylarks. Ecological Modelling 85:67-73.
Droesen, W. J. 1996. Formalisation of ecohydrological expert knowledge applying fuzzy techniques. Ecological Modelling 85:75-81.

DiToro, D. M., and J. P. Connolly. 1980. Mathematical models of water quality in large lakes. Part 2: Lake Erie. Report No. EPA-600/3-80-065. U.S. EPA, Large Lakes Research Station, ERL-Duluth, Grosse Ile, Michigan, USA.

Ducey, M. J., and B. C. Larson. 1999. A fuzzy set approach to the problem of sustainability. Forest Ecology and Management 115:29-40.

Eden, C. 1988. Cognitive mapping. European Journal of Operational Research 36:1-13.

Enea, M., and G. Salemi. 2001. Fuzzy approach to environmental impact evaluation. Ecological Modelling 136:131147.

Freyer, B., Y. Reisner, and D. Zuberbuhler. 2000. Potential impact model to assess agricultural pressure to landscape ecological functions. Ecological Modelling 130:121-129.

Gauch, H. G. 1982. Multivariate analyses in community ecology. Cambridge University Press, New York, New York, USA.

Harris, H. J., R. B. Wenger, V. A. Harris, and D. S. DeVault. 1994. A method for assessing environmental risk: a casestudy of Green Bay, Lake Michigan, USA. Environmental Management 18:295-306.

Hartman, W. L. 1972. Lake Erie: effects of exploitation, environmental changes and new species on the fisheries resources. Journal of the Fishery Resources Board of Canada 29:899-912.

Holland, R. E., T. H. Johengen, and A. M. Beeton. 1995. Trends in nutrient concentration in Hatchery Bay, western Lake Erie, before and after Dreissena polymorpha. Canadian Journal of Fisheries and Aquatic Sciences 52:12021209.

Holling, C. S. 1978. Adaptive environmental assessment and management. J. Wiley, London, UK.

Hutchinson, G. E. 1978. An introduction to population ecology. Yale University Press, New Haven, Connecticut, USA.

Johnson, B. L., H. E. Hicks, and C. T. DeRosa. 1999. Key environmental human health issues in the Great Lakes and St. Lawrence River basins. Environmental Research 80:S12(Part 2).

Jongman, R. H. G., C. J. F. ter Braak, and O. F. R. van Tongeren. 1995. Data analysis in community and landscape ecology. Cambridge University Press, Cambridge, UK.

Kosko, B. 1992. Neural networks and fuzzy systems: a dynamical systems approach to machine intelligence. Prentice Hall, Englewood Cliffs, New Jersey, USA.

Lake Erie Lakewide Management Plan. 2000. Lake Erie Lakewide Management Plan 2000 report. Ohio Environmental Protection Agency, Columbus, Ohio, USA.

Lam, D. C. L., and T. J. Simons. 1976. Numerical computations of advective and diffusive transports of chloride, 1970. Journal of the Fisheries Resources Board of Canada 33:537-549.

Leach, J. H., and S. J. Nepszy. 1976. The fish community in Lake Erie. Journal of the Fisheries Research Board of Canada 33:622-638.

Levins, R. 1966. The strategy of model building in population biology. American Scientist 54:421-431.

Locci, A. B., and J. F. Koonce. 1999. A theoretical analysis of food web constraints on walleye dynamics in Lake Erie. Pages 497-510 in M. Munawar, T. Edsall, and I. F. Munawar, editors. State of Lake Erie: past, present, and future. Backhuys, Leiden, The Netherlands.

Ludsin, S. A., P. Bertram, H. Biberhofer, J. J. H. Ciborowski, M. Colavecchia, S. George, B. F. Hobbs, R. L. Knight, and P. A. Ryan. 2002. Identification of future ecosystem management objectives for Lake Erie: a fuzzy-cognitive modeling approach. In J. J. H. Ciborowski, M. N. Charlton, R. 
G. Kreis, Jr., and J. M. Reutter, editors. Lake Erie at the millennium: changes, trends, and trajectories. Canadian Scholars' Press, Toronto, Canada.

Ludsin, S. A., M. W. Kershner, K. A. Blocksom, R. L. Knight, and R. A. Stein. 2001. Life after death in Lake Erie: nutrient controls drive fish species richness, rehabilitation. Ecological Applications 11:731-746.

Mackinson, S. 2001. Integrating local and scientific knowledge: an example in fisheries science. Environmental Management 27:533-545.

Makarewicz, J. C., and P. Bertram. 1991. Evidence for the restoration of the Lake Erie ecosystem. BioScience 41:216223.

Marchant, T. 1999. Cognitive maps and fuzzy implications. European Journal of Operational Research 114:626-637.

Mas-Colell, A., M. Whinston, and J. R. Green. 1995. Microeconomic theory. Oxford University Press, New York, New York, USA.

Matlock, M. D., D. E. Storm, J. G. Sabbagh, C. T. Hann, M. D. Smolen, and S. L. Burks. 1994. An ecological risk assessment paradigm using the Spatially Integrated Mode for Phosphorus Loading and Erosion (SIMPLE). Journal of Aquatic Ecosystem Health 3:287-294.

McCune, B., and M. J. Mefford. 1995. PC-ORD: multivariate analysis of ecological data. Version 2.0. MjM Software Design, Gleneden Beach, Oregon, USA.

McGlade, J. M., editor. 1999. Advanced ecological theory: principles and applications. Blackwell Science, Oxford, UK.

McNeill, F., and E. Thro. 1994. Fuzzy logic: a practical approach. Academic Press, New York, New York, USA.

McQueen, D. J., J. R. Post, and E. L. Mills. 1986. Trophic relationships in fresh-water pelagic ecosystems. Canadian Journal of Fisheries and Aquatic Sciences 43:1571-1581.

Meesters, E. H., R. P. M. Bak, S. Westmacott, M. Ridgley, and S. Dollar. 1998. A fuzzy logic model to predict cora reef development under nutrient and sediment stress. Conservation Biology 12(5):957-965.

Mills, E. L., J. H. Leach, J. T. Carlton, and C. L. Secor. 1993. Exotic species in the Great Lakes: a history of biotic crisis and anthropogenic introductions. Journal of Great Lakes Research 19:1-54.

Minns, C. K. 1992. Use of models for integrated assessment of ecosystem health. Journal of Aquatic Ecosystem Health 1:109-118

Munda, G. 1995. Multicriteria evaluation in a fuzzy environment: theory and applications in ecological economics. Physica-Verlag Heidelberg, Heidelberg, Germany.

Ney, J. J. 1996. Oligotrophication and its discontents: effects of reduced nutrient loading on reservoir fisheries. American Fisheries Society Symposium 16:285-295.

Nicholls, K. H., and C. Tudorancea. 2001. Application of fuzzy cluster analysis to Lake Simcoe crustacean zooplankton community structure. Canadian Journal of Fisheries and Aquatic Sciences 58:231-240.

Novello-Hogarth, A., and J. M. McGlade. 1997. Sustainable management of coastal resources. HYDRO International 1(October):6-9.

Parashar, A., R. Paliwal, and P. Rambabu. 1997. Utility of fuzzy cross-impact simulation in environmental assessment. Environmental Impact Assessment Review 40:427447.

Pedrycz, W. 1991a. Processing in relational structures: fuzzy relational equations. Fuzzy Sets and Systems. 40:77-106.

Pedrycz, W. 1991b. Fuzzy modeling: fundamentals, construction, and evaluation. Fuzzy Sets and Systems 41:1-15.
Radomski, P. J., and T. J. Goeman. 1996. Decision making and modeling in freshwater sport-fisheries management. Fisheries 21(12):6-11.

Ramsey, F. L. 1986. A fable of PCA. American Statistician 40:323-324.

Redfield, G. W. 2000. Ecological research for aquatic science and environmental restoration in south Florida. Ecological Applications 10:990-1005.

Roberts, D. W. 1989. Analysis of forest succession with fuzzy graph theory. Ecological Modelling 45:261-274.

Ryan, P. A., L. D. Witzel, J. R. Paine, M. J. Freeman, M. Hardy, S. Scholten, J. L. Sztramko, and R. MacGregor. 1999. Recent trends in fish populations in eastern Lake Erie in relation to changing trophic state and food web. Pages 241-289 in M. Munawar and T. Edsall, editors. State of Lake Erie (SOLE): past, present, and future. Backhuys, Leiden, The Netherlands.

Salski, A. 1992. Fuzzy knowledge-based models in ecological research. Ecological Modelling 63:103-112.

Salski, A., O. Franzle, and P. Kandzia, editors. 1996. Fuzzy logic in ecological modelling. Ecological Modelling 85:198 .

Silvert, W. 2000. Fuzzy indices of environmental conditions. Ecological Modelling 130(1-3):111-119.

Simons, T. J. 1976. Continual dynamical computations of water transports in Lake Erie for 1970. Journal of the Fisheries Research Board of Canada 33:371-384.

Smith, P. N. 1999. Environmental project evaluation based on fuzzy relational equations. Journal of Environmental Systems 27:113-125.

Stansbury, J., I. Bogardi, and E. Z. Stakhiv 1999. Risk-cost optimization under uncertainty for dredged material disposal. Journal of Water Resources Planning and Management 125:342-351.

Stockner, J. G., E. Rydin, and P. Hyenstrand. 2000. Cultural oligotrophication: causes and consequences for fishery resources. Fisheries 25(5):7-14.

Sun, R. 1994. A neural network model of causality. IEEE Transactions on Neural Networks 5:604-611.

Tester, J. R., A. M. Starfield, and L. E. Frelich. 1997. Modeling for ecosystem management in Minnesota pine forests. Biological Conservation 80:313-324.

Thomann, R. V. 1998. The future "golden age" of predictive models for surface water quality and ecosystem management. Journal of Environmental Engineering (American Society of Civil Engineers) 124:94-103.

Tsadiras, A. K., and K. G. Margaritis. 1999. An experimental study of the dynamics of the certainty neuron fuzzy cognitive maps. Neurocomputing 24:95-116.

Ulengin, F., and I. Topcu. 1997. Cognitive map: KBDSS integration in transportation planning. Journal of the Operational Research Society 48:1065-1078.

van der Werf, H. M. G., and C. Zimmer. 1998. An indicator of pesticide environmental impact based on a fuzzy expert system. Chemosphere 36:2225-2249.

Walters, C., J. Korman, L. E. Stevens, and B. Gold. 2000. Ecosystem modeling for evaluation of adaptive management in the Grand Canyon. Conservation Ecology 2(4):914.

Ward, J. 1973. Hierarchical grouping to optimize an objective function. Journal of the American Statistical Association 58:236-244.

Wu, H. I., B. L. Li, R. Stoker, and Y. Li. 1996. A semi-arid grazing ecosystem simulation model with probabilistic and fuzzy parameters. Ecological Modelling 90:147-160.

Zadeh, L. 1965. Fuzzy sets. Information and Control 8:338353. 